\title{
Brief adult respiratory system health status scale-community version (BARSHSS-CV): developing and evaluating the reliability and validity
}

Hongzhe Dou', Yuejia Zhao', Yanhong Chen'1, Qingchun Zhao', Bo Xiao², Yan Wang ${ }^{3}$, Yonghe Zhang ${ }^{3}$, Zhiguo Chen ${ }^{3}$, Jie Guo ${ }^{3}$ and Lingwei Tao ${ }^{4^{*}}$ (D)

\begin{abstract}
Background: The evaluation of respiratory system health status in hospitalized patients is usually based on many laboratory examinations and imaging examinations. Medical examinations require a lot of manpower, material resources, financial resources, and may cause a certain degree of mechanical damage and radiation damage. It is not easily used widely and economically to assess the respiratory health status of community adults. Therefore, researchers developed a brief adult respiratory system health status scale-community version (BARSHSS-CV) and tested its reliability and validity.
\end{abstract}

Methods: Using clinical characteristics and pathogenic factors of respiratory system diseases as a theoretical basis and through reference to relevant literature, researchers developed an initial scale. A randomized cluster sampling strategy was used to recruit adults in the communities of Baoding City, Shijiazhuang City, Cangzhou city and Chifeng City in China. Researchers randomly selected 1 district from each city. Subsequently, 4 communities were respectively randomly selected from 4 districts. Then, researchers conducted the questionnaire survey in 4 communities. Finally, researchers investigated 615 community adults. 584 valid questionnaires were recovered. By applying exploratory factor analysis, confirmatory factor analysis, content validity index, Cronbach's a coefficient, mean inter-item correlation coefficient and test-retest reliability, researchers tested the reliability and validity of scale and created the final BARSHSS-CV.

Results: BARSHSS-CV Cronbach's $a=0.951$, content validity $=0.933$, test-retest reliability $=0.963$ and factor cumulative contribution rate $=67.168 \%$ by exploratory factor analysis. By confirmatory factor analysis, Chi square value (X2) was 442.117, degrees of freedom ( $\mathrm{df}$ ) was 161, Chi square value/degrees of freedom (X2/df) was 2.746, root-mean-square error of approximation (RMSEA) was 0.065, goodness of fit index (GFI) was 0.902, incremental fit index (IFI) was 0.955, comparative fit index (CFI) was 0.955, normed fit index (NFI) was 0.931, Tueker-Lewis index (TLI) was 0.947. BARSHSS-CV consisted of 20 items and 3 dimensions.

Conclusions: BARSHSS-CV with good test-retest reliability and content/construct validity is a brief and economical tool for assessing the state of respiratory system amongst adult communities. BARSHSS-CV may help medical staff in community primary medical institutions quickly, conveniently and economically assess the status of respiratory system and the main problems of respiratory system in community adults.

Keywords: Community, Adult, Respiratory system, Health level, Reliability, Validity

\footnotetext{
*Correspondence: taolingwei115@163.com

${ }^{4}$ School of Public Health, Capital Medical University, No.10 Xitoutiao,

Youanmenwai, Beijing 100069, China

Full list of author information is available at the end of the article
}

(c) The Author(s). 2018 Open Access This article is distributed under the terms of the Creative Commons Attribution 4.0 International License (http://creativecommons.org/licenses/by/4.0/), which permits unrestricted use, distribution, and reproduction in any medium, provided you give appropriate credit to the original author(s) and the source, provide a link to the Creative Commons license, and indicate if changes were made. The Creative Commons Public Domain Dedication waiver (http://creativecommons.org/publicdomain/zero/1.0/) applies to the data made available in this article, unless otherwise stated. 


\section{Background}

Globally, the issue of air pollution has impacted the health of millions of individuals. [1]. Air pollution directly contributes to many serious effects on public health in China The National Plan on Air Pollution Control was formulated by the Chinese government in 2012, which set goals and measures to prevent and control air pollution. The first plan was proposed in 2013, which projected that by 2017 the quality of air would be dramatically improved [2]. Infectious diseases are an important threat to human health, and infectious diseases of respiratory system are the most common [3]. Chronic obstructive pulmonary disease (COPD) is an important cause of premature mortality, and asthma prevalence also continues to increase in community adults $[4,5]$. Respiratory system diseases are very common diseases contributing to the world's global disease burden. Collectively respiratory system diseases of adults are associated with a significant burden on healthcare systems, as well as on society $[6,7]$. Effective assessment and management plans have been shown to reduce morbidity and mortality from respiratory system diseases among community adults [7]. With the increase of atmospheric concentrations of $\mathrm{SO}_{2}, \mathrm{CO}$ and suspended particles, the variation of pathogenic microorganisms, and the increase of drug-resistant bacteria, the number of people suffering from respiratory system diseases and the mortality of related diseases have increased significantly in the community $[3,8,9]$.

At present, much research is focused on the diagnosis and treatment of specific respiratory system diseases in hospitalized patients. However, there are relatively few studies on the respiratory system health level of adults in the community $[10,11]$. The evaluation of respiratory system health status in hospitalized patients is usually based on a large number of laboratory examinations and imaging examinations. For example, in blood tests an increase in the number of white blood cells and an increase in the proportion of neutrophils may indicate bacterial infection. In the sputum examination, the drug sensitivity test for bacteria in sputum can guide clinical medication. Chest X-ray examination, CT examination and MRI examination are helpful in the diagnosis of respiratory system organic lesions [3]. However, these medical examinations need to rely on many medical devices and professional technicians. Due to manpower, material resource, financial resource and damage of medical examinations, community-based adults generally can't receive these medical examinations frequently. Furthermore, it is difficult to be widely and economically used to assess the respiratory health status of adults in the community. Therefore, our research team developed a brief adult respiratory system health status scale-community version (BARSHSS-CV) and tested its reliability and validity. The validity reflects whether the measurement tool effectively measures what the researcher wants to measure. It mainly evaluates the accuracy and correctness of scale. The reliability reflects the measured value variation caused by random errors in the measurement process. It mainly evaluates the accuracy and stability of scale [12]. Potentially the BARSHSS-CV may act as a brief, rapid, effective and economical evaluation tool for extensively assessing the respiratory system health status among community adults in the future.

\section{Methods \\ Development of BARSHSS-CV-I}

Using common clinical characteristics and pathogenic factors of the respiratory system diseases as the theoretical basis [3] and through extensive reference to relevant literature, an initial pool of 40 items was generated (Additional file 1). After analyzing and discussing, the research team retained 26 items and developed an initial scale (brief adult respiratory system health status scale-community version-I, BARSHSS-CV-I) (Additional file 2), which included 26 items and 4 dimensions. The four dimensions were named: Dimension 1, mild respiratory system symptom; Dimension 2, severe system respiratory symptom; Dimension 3, medical history; Dimension 4, susceptibility factor. All of the items were presented in simple and reader-friendly language so that the adults in the community could clearly understand the meaning of each item $[13,14]$.

\section{Development of BARSHSS-CV-II}

The research team invited six related experts from the medical university and the hospital (including two clinical doctors, two clinical nurses and two public health experts) to assess the scale content validity (face validity). 3 , on the evaluation standard represented a strong relation, whilst 1 represented no relation. The experts were asked to describe if they felt the item was "strongly related" or "not related" to "adult respiratory system health status" (i.e. the theme of the overall questionnaire). Based on the results of the expert review, 6 items of BARSHSS-CV-Iwere deleted to form BARSHSS-CV-II which included 20 items and 4 dimensions with the unchanged names of each dimension. Three experts rated 1 point (not related) for six items which were deleted. The deleted items were: Q5. I often feel weak; Q6. I often feel powerless; Q7. I often feel my chest uncomfortable when I stay in a hot room for a long time. Q8. I often feel my chest uncomfortable when I stay in a cold room for a long time; Q20. My chest had been traumatized in the past; Q21.I received the surgical treatment of the chest in the past. These experts thought that Q5 and Q6 were common symptoms of many diseases and were not specific symptoms of respiratory system diseases. These experts 
thought that when a healthy person stayed in a hot or cold room for a long time, the person might also feel uncomfortable. Therefore, Q7 and Q8 were not specific symptoms of respiratory system diseases. These experts thought that chest trauma and chest surgery might damage the muscles and bones of chest, but they did not necessarily damage the respiratory system. Therefore, Q20 and Q21 were also deleted. Finally, this scale retained 20 items (Table 1). Each item was rated according to a 5 -point Likert scale $(5=$ completely agree; $4=$ agree most; $3=$ moderately agree; $2=$ agree a small part, $1=$ disagree). In the way of reverse scoring, the scores were 1 point, 2 points, 3 points, 4 points, and 5 points, respectively. The total score of scale was the sum of all items' scores. The higher the score, the better the community adult respiratory system health status. Subsequently, 5 community adults were asked to complete BARSHSS-CV-II to test scale wording and comprehension so that we could improve item wording and statement expression. Every item in the BARSHSS-CV-IIwas presented in simple and reader-friendly language so that the community adults could clearly understand the meaning of items $[13,14]$.

\section{Large sample testing and development of the final BARSHSS-CV}

A randomized cluster sampling strategy was used to recruit adults in the communities of Baoding City, Shijiazhuang City, Cangzhou City and Chifeng City in China,

Table 1 The content of the brief adult respiratory system health status scale-community version (BARSHSS-CV)

\begin{tabular}{|c|c|c|c|c|c|c|}
\hline Dimensions & Items & $\begin{array}{l}\text { Completely agree } \\
5\end{array}$ & $\begin{array}{l}\text { Agree most } \\
4\end{array}$ & $\begin{array}{l}\text { Moderately agree } \\
3\end{array}$ & $\begin{array}{l}\text { Agree a small part } \\
2\end{array}$ & $\begin{array}{l}\text { Disagree } \\
1\end{array}$ \\
\hline \multirow{4}{*}{$\begin{array}{l}\text { Mild respiratory system } \\
\text { symptom }\end{array}$} & Q1. I often catch a cold. & 5 & 4 & 3 & 2 & 1 \\
\hline & Q2. I often cough. & 5 & 4 & 3 & 2 & 1 \\
\hline & Q3. I often feel phlegm in my throat. & 5 & 4 & 3 & 2 & 1 \\
\hline & Q4. I often feel chest tightness. & 5 & 4 & 3 & 2 & 1 \\
\hline \multirow[t]{9}{*}{$\begin{array}{l}\text { Severe respiratory } \\
\text { system symptom }\end{array}$} & $\begin{array}{l}\text { Q5. I often have whooping or whistling } \\
\text { sounds when I breathe. }\end{array}$ & 5 & 4 & 3 & 2 & 1 \\
\hline & $\begin{array}{l}\text { Q6. I often have difficulty breathing } \\
\text { when I sleep at night. }\end{array}$ & 5 & 4 & 3 & 2 & 1 \\
\hline & $\begin{array}{l}\text { Q7. I often walk slowly due to the } \\
\text { dyspnea. }\end{array}$ & 5 & 4 & 3 & 2 & 1 \\
\hline & $\begin{array}{l}\text { Q8. I often have difficulty breathing } \\
\text { after I perform mild activity. }\end{array}$ & 5 & 4 & 3 & 2 & 1 \\
\hline & $\begin{array}{l}\text { Q9. I am now suffering from a respiratory } \\
\text { system disease. }\end{array}$ & 5 & 4 & 3 & 2 & 1 \\
\hline & $\begin{array}{l}\text { Q10. When I suffer from a respiratory } \\
\text { system disease, it takes a long time } \\
\text { to recover. }\end{array}$ & 5 & 4 & 3 & 2 & 1 \\
\hline & $\begin{array}{l}\text { Q11. I often cannot work, learn, or carry } \\
\text { out outdoor activities due to respiratory } \\
\text { system diseases. }\end{array}$ & 5 & 4 & 3 & 2 & 1 \\
\hline & $\begin{array}{l}\text { Q12. I often go to the hospital for } \\
\text { examinations and treatments due to } \\
\text { respiratory system diseases. }\end{array}$ & 5 & 4 & 3 & 2 & 1 \\
\hline & $\begin{array}{l}\text { Q13. I often use some drugs for the } \\
\text { treatment of respiratory system diseases. }\end{array}$ & 5 & 4 & 3 & 2 & 1 \\
\hline \multirow[t]{7}{*}{ Susceptibility factor } & Q14. I often smoke. & 5 & 4 & 3 & 2 & 1 \\
\hline & Q15. My family members often smoke. & 5 & 4 & 3 & 2 & 1 \\
\hline & $\begin{array}{l}\text { Q16. My family members often suffered } \\
\text { from respiratory system diseases in the past. }\end{array}$ & 5 & 4 & 3 & 2 & 1 \\
\hline & $\begin{array}{l}\text { Q17. I often suffered from respiratory } \\
\text { system diseases in the past. }\end{array}$ & 5 & 4 & 3 & 2 & 1 \\
\hline & Q18. I am often in a haze environment. & 5 & 4 & 3 & 2 & 1 \\
\hline & $\begin{array}{l}\text { Q19. My work environment is full of } \\
\text { dust or harmful gases. }\end{array}$ & 5 & 4 & 3 & 2 & 1 \\
\hline & $\begin{array}{l}\text { Q20. I am allergic to pollen, dust, animal } \\
\text { fur, or some gases. }\end{array}$ & 5 & 4 & 3 & 2 & 1 \\
\hline
\end{tabular}


between June 2015 and May 2016. Four cities were selected because air pollution in each of these cities is at a serious level [15]. Researchers randomly selected 1 district from each city, a total of 4 districts. Subsequently, 4 communities were respectively randomly selected from these 4 districts. Then, the researchers conducted the questionnaire survey of adults in the 4 communities. The researchers planned to investigate 150 community adults in each community, a total of 600 community adults. Finally, the research team investigated 615 adults in the communities. Inclusion criteria: (1) Community adults that have a satisfactory level of understanding, can correctly understand the contents of questionnaires their respective answers. (2) Not suffering from brain diseases, mental diseases or other serious diseases. Sample size determination: When we evaluated the hypothesized measurement model, the exploratory factor analysis (EFA) and the confirmatory factory analysis (CFA) were appropriately used. 10-15 individuals per item were included in the sample size for the factor analysis. Factor analysis results were relatively more stable and reliable in cases where the sample size is greater than 20 individuals per item [16]. Since this scale contained 20 items, the large sample should be more than 400. However, to increase the results reliability and stability, after comprehensively considering the feasibility of this research, we increased the number of samples. Therefore, finally, a total of 615 questionnaires were distributed. 12 adults did not complete the demographic characteristics questionnaire or this scale. 19 adults did not complete this scale. Finally, 584 complete and valid questionnaires were recovered, and the valid recovery rate was $94.96 \%(94.96 \%=584 / 615)$. By analyzing the data of 584 valid questionnaires, the researchers tested the scale internal reliability and content/construct validity and developed the final scale (BARSHSS-CV). The test-retest reliability of BARSHSS-CV was tested in the subsample of 50 participants from the large sample over two week's interval [17]. By asking if the participants had a change in health status during the 2 week interval, researchers determined that the participants had stable health status during the 2 week interval between test and re-test.

\section{Ethical consideration and survey method}

The Hebei province federation of social science circles approved this study (Permit Number: 201501808). This research was conducted according to the standards of the Declaration of Helsinki. The research team explained the purpose of this study to the adults in the communities. After obtaining verbal consent from the community-based adults to participate in the study, researchers provided information to participants on how to complete the questionnaires. The researchers distributed and recovered the questionnaires in the communities. The questionnaires used standardized language and instructions.

\section{Statistical analysis}

The researchers used Epidata3.1 software to input the data twice and completed a consistency check. AMOS 17.0 software and SPSS 17.0 were used to analyze the data. This study used the descriptive statistics (frequency and percentage) to analyze the characteristics of community adults. Testing methods for reliability and validity [12]: (1) The confirmatory factor analysis (CFA) and the exploratory factor analysis (EFA) were applied to assess the construct validity of scale. (2) The content validity index (CVI) was applied to evaluate the content validity of scale. (3) Mean inter-item correlation coefficient (MIIC) and Cronbach's $\alpha$ coefficient and test-retest reliability were applied to assess the scale reliability. The level of significance was $p<0.05$. The retention of factors were based on the following criteria: (1) The scree plot of EFA; (2) Eigenvalues greater than 1; (3) The factor loadings above 0.500 ; (4) Items equal to or more than 2 being retained [17]. The model fit of scale structure was considered acceptable if Chi square value/degrees of freedom $\left(\mathrm{x}^{2} / \mathrm{df}\right)<3$, root-mean-square error of approximation (RMSEA) <0.08, goodness of fit index (GFI) > 0.90 , incremental fit index (IFI) $>0.90$, comparative fit index $(\mathrm{CFI})>0.90$, normed fit index $(\mathrm{NFI})>0.90$, and Tueker-Lewis index (TLI) $>0.90[14,17,18]$.

\section{Results}

\section{Characteristics of the large sample}

A total of 615 community adults were given questionnaires, 584 valid questionnaires were recovered; the valid recovery rate was $94.96 \%$. These community adults included 258 men (44.2\%) and 326 women (55.8\%) from urban area (57.4\%) and rural area (42.6\%). They included Han race $(93.8 \%)$ and minority $(6.2 \%)$. These community adults were classified into four age groups including < $20,20-39,40-59$ and $\geq 60$, accounting for $17.1 \%, 47.4 \%$, $18.5 \%$ and $17.0 \%$ respectively. These community adults were classified into three monthly income groups including < 800 RMB, 800-1499 RMB and $\geq 1500$ RMB, accounting for $24.7 \%, 40.9 \%$ and $34.4 \%$ respectively. The characteristics of the large sample data are shown in detail in Table 2.

\section{Testing of reliability and validity Construct validity}

Exploratory factor analysis (EFA) BARSHSS-CV-II was tested in the 584 participants. To carry out BARSHSS-CV-IIexploratory factor analysis, we used the principal component analysis (PCA) and maximum variance orthogonal rotation methods. The Bartlett 
Table 2 Characteristic data of the large sample

\begin{tabular}{|c|c|c|}
\hline Characteristics & Subjects (n) & $\%$ \\
\hline \multicolumn{3}{|l|}{ Gender } \\
\hline Male & 258 & 44.2 \\
\hline Female & 326 & 55.8 \\
\hline \multicolumn{3}{|l|}{ Age } \\
\hline $18 \sim$ & 100 & 17.1 \\
\hline $20 \sim$ & 277 & 47.4 \\
\hline $40 \sim$ & 108 & 18.5 \\
\hline $60 \sim$ & 99 & 17.0 \\
\hline \multicolumn{3}{|l|}{ Race } \\
\hline Han & 548 & 93.8 \\
\hline Minority & 36 & 6.2 \\
\hline \multicolumn{3}{|l|}{ Monthly income (RMB) } \\
\hline$<800$ & 144 & 24.7 \\
\hline $800 \sim$ & 239 & 40.9 \\
\hline $1500 \sim$ & 201 & 34.4 \\
\hline \multicolumn{3}{|l|}{ Education } \\
\hline Primary school & 70 & 12.0 \\
\hline High school & 261 & 44.7 \\
\hline Junior college & 60 & 10.3 \\
\hline Undergraduate and above & 193 & 33.0 \\
\hline \multicolumn{3}{|l|}{ Occupation } \\
\hline Manual worker & 392 & 67.1 \\
\hline Mental worker & 192 & 32.9 \\
\hline \multicolumn{3}{|l|}{ Do you have a religious faith } \\
\hline No & 541 & 92.6 \\
\hline Yes & 43 & 7.4 \\
\hline \multicolumn{3}{|l|}{ Place of residence } \\
\hline Urban area & 335 & 57.4 \\
\hline Rural area & 249 & 42.6 \\
\hline \multicolumn{3}{|l|}{ Physical examination frequency } \\
\hline Never & 186 & 31.8 \\
\hline Once a few years & 188 & 32.2 \\
\hline Once a year & 168 & 28.8 \\
\hline A few times a year & 42 & 7.2 \\
\hline
\end{tabular}

The characteristic data of the large sample are presented as frequency and percentage

sphericity test value was $8705.183(\mathrm{df}=190, P<0.001)$ and KMO value (Kaiser-Meyer-Olkin value) was 0.951 . From our findings it was clear that the data were suitable for factor analysis. Furthermore, we carried out factor extraction using undefined factor number conditions. The cumulative variance contribution rate of factors was 67.168\%. Three factors (Eigenvalue>1) were extracted. The factor analysis scree plot of BARSHSS-CV-IIindicated an inflection point between the 3rd factor and the 4th factor. The scree plot of EFA indicated the 3-factor structure was suitable (Fig. 1). Through the above comprehensive analysis, the research team thought the final version of BARSHSS-CV contained three factors and 20 items. Final three factors were renamed: Factor 1, mild respiratory system symptom (4 items); Factor 2, severe respiratory system symptom ( 9 items); Factor 3, susceptibility factor (7 items) (Table 3). The content of the brief adult respiratory system health status scale-community version (BARSHSS-CV) is shown in the Table 1.

Confirmatory factor analysis (CFA) To determine the most appropriate BARSHSS-CV dimensional structure, the researcher used the AMOS17.0 software and randomly selected a 70\% sample size of 409 samples and used the maximum likelihood method to perform BARSHSS-CV confirmatory factor analysis of the 20-item and 3-factor structure. The value of Chi square value $(x 2)$ was 442.117 . The value of degrees of freedom (df) was 161 . The value of Chi square value/degrees of freedom ( $\mathrm{x} 2 / \mathrm{df})$ was 2.746 . The value of root-mean-square error of approximation (RMSEA) was 0.065 . The value of goodness of fit index (GFI) was 0.902 . The value of incremental fit index (IFI) was 0.955 . The value of comparative fit index (CFI) was 0.955 . The value of normed fit index (NFI) was 0.931 . The value of Tueker-Lewis index (TLI) was 0.947 (Table 4). The standard path and parameter estimation of CFA was in the Fig. 2.

\section{Internal consistency test}

Correlation coefficients of factors in the BARSHSS-CV ranged from 0.416 to $0.699(P<0.01)$. Correlation coefficients between factors and the whole scale of BARSHSS-CV ranged from 0.750 to $0.922(P<0.01)$. (Table 5).

\section{Content validity}

Expert evaluation suggests the scale's content validity index (CVI) was 0.933 and each of the items CVI ranged from 0.667 to 1.00 . Five community adults reported that they could clearly understand the meaning of each item without difficulty as soon as we improved item wording and statement expression.

\section{Reliability}

The Cronbach's $\alpha$ coefficient of entire BARSHSS-CV was 0.951 , and the Cronbach's $\alpha$ coefficients of all factors were from 0.873 to 0.945 . The mean inter-item correlation coefficient value (MIIC) of entire BARSHSS-CV was 0.500 . MIIC values of all factors were from 0.511 to 0.656 . The entire BARSHSS-CV test-retest reliability coefficient was 0.963 , and the test-retest reliability coefficient of each factor were from 0.931 to 0.977 (Table 6). 


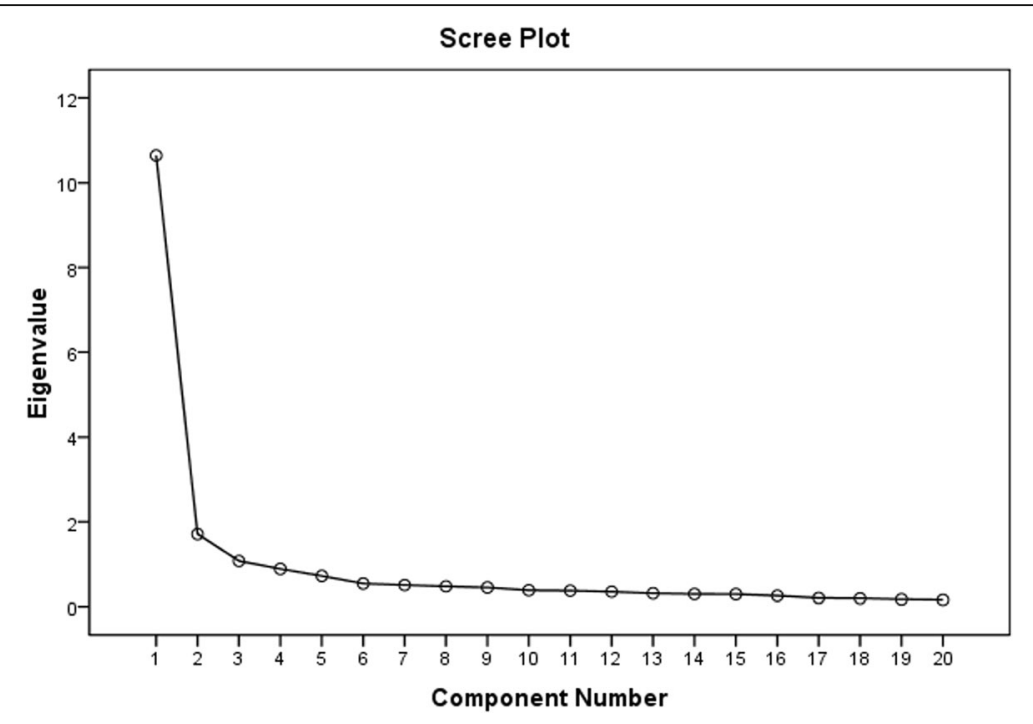

Fig. 1 Scree plot of exploratory factor analysis

Table 3 Rotated component matrix, eigenvalue and cumulative variance contribution rate

\begin{tabular}{|c|c|c|c|c|}
\hline & Items & Factor 2 & Factor 3 & Factor 1 \\
\hline & Q1 & - & - & 0.832 \\
\hline & Q2 & - & - & 0.849 \\
\hline & Q3 & _- & _- & 0.755 \\
\hline & Q4 & - & - & 0.637 \\
\hline & Q5 & 0.729 & _- & - \\
\hline & Q6 & 0.741 & - & - \\
\hline & Q7 & 0.715 & - & - \\
\hline & Q8 & 0.639 & - & - \\
\hline & Q9 & 0.729 & _- & - \\
\hline & Q10 & 0.692 & - & - \\
\hline & Q11 & 0.723 & - & - \\
\hline & Q12 & 0.761 & - & - \\
\hline & Q13 & 0.729 & - & - \\
\hline & Q14 & - & 0.642 & - \\
\hline & Q15 & _- & 0.587 & _- \\
\hline & Q16 & - & 0.750 & - \\
\hline & Q17 & _- & 0.708 & _- \\
\hline & Q18 & - & 0.707 & - \\
\hline & Q19 & - & 0.740 & - \\
\hline & Q20 & - & 0.641 & - \\
\hline Eigenvalue & & 5.729 & 4.503 & 3.202 \\
\hline Variance contribution rate (\%) & & 28.643 & 22.515 & 16.011 \\
\hline Cumulative variance contribution rate (\%) & & 28.643 & 51.158 & 67.168 \\
\hline Factor naming & & Severe respiratory system symptom & Susceptibility factor & Mild respiratory system symptom \\
\hline
\end{tabular}

Factor 1, mild respiratory system symptom; Factor 2, severe system respiratory symptom; Factor 3, susceptibility factor. This symbol '_'indicated that values were less than 0.500 . Suppress absolute values less than 0.500 
Table 4 The results of confirmatory factor analysis

\begin{tabular}{lllllllll}
\hline$X^{2}$ & $\mathrm{df}$ & $X^{2} / \mathrm{df}$ & RMSEA & $\mathrm{GFI}$ & $\mathrm{IFI}$ & $\mathrm{CFI}$ & $\mathrm{NFI}$ & $\mathrm{TLI}$ \\
\hline 442.117 & 161 & 2.746 & 0.065 & 0.902 & 0.955 & 0.955 & 0.931 & 0.947
\end{tabular}

$\mathrm{x} 2$, Chi square value; $\mathrm{df}$, degrees of freedom; $\mathrm{x} / \mathrm{df}$, Chi square value/degrees of freedom; RMSEA root-mean-square error of approximation, GFI goodness of fit index, IFI incremental fit index, CFI comparative fit index, NFI normed fit index, TLI Tueker-Lewis index

\section{Discussion}

Worldwide, the older health care model is gradually being transformed; we are shifting from a model that views medical workers as having the leading role in patient care interactions into a newer modern model that involves patients in decisions relating to their health management $[19,20]$. The medical policy guidelines and medical system in China mostly focus on the diagnosis, treatment and nursing of the specific respiratory system diseases. The BARSHSS-CV may provide a way to help medical staff in community settings to conveniently and economically assess respiratory system health. Medical staff can also implement targeted intervention and health guidance for the respiratory system health care among community adults to help community adults
Table 5 Correlation coefficients among the factors of BARSHSS$\mathrm{CV}$ and between the factors and the total scale of BARSHSS-CV

\begin{tabular}{llll}
\hline Factor & Factor 2 & Factor 3 & BARSHSS-CV \\
\hline Factor 1 & $0.591^{* *}$ & $0.416^{* *}$ & $0.750^{* *}$ \\
Factor 2 & - & $0.699^{* *}$ & $0.922^{* *}$ \\
Factor 3 & - & - & $0.827^{* *}$
\end{tabular}

Factor 1 , mild respiratory system symptom; Factor 2 , severe system respiratory symptom; Factor 3, susceptibility factor. This symbol '_'indicated no such correlation coefficient. ${ }^{* *} P<0.01$

establish healthy protection awareness, establish a healthy lifestyle, and reduce the incidence of respiratory system diseases to reduce the related medical burden on the government, society, family and themselves individually [21, 22].

Both exploratory factor analysis and confirmatory factor analysis are used when a hypothesized measurement model is assessed in the study. The sample size in the study should be 10-15 subjects per item for factor analysis of scale [23]. The sample size of our research was enough for factor analysis of BARSHSS-CV. In the exploratory factor analysis, to assess the suitability of

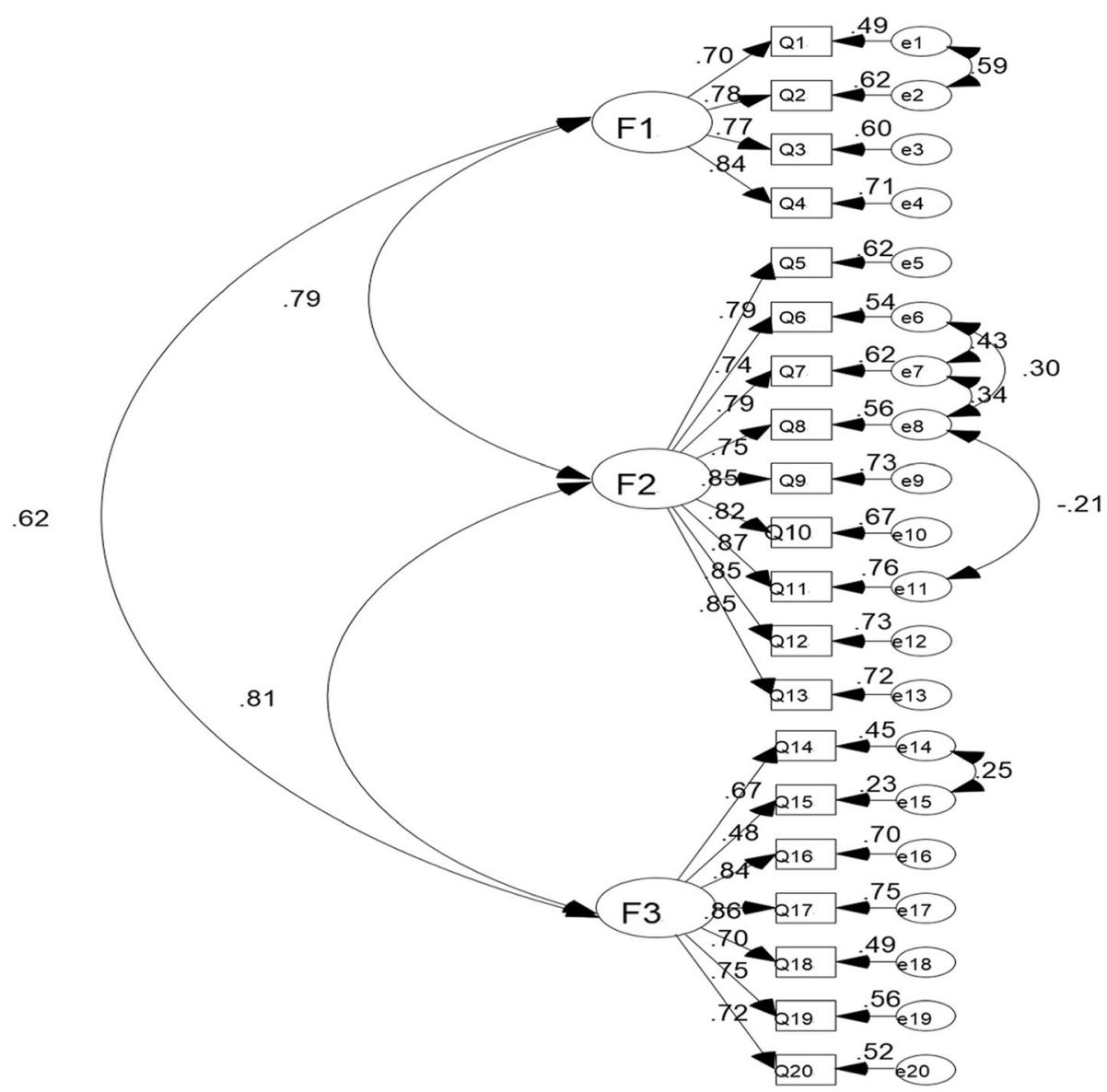

Fig. 2 Standard path and parameter estimation of confirmatory factor analysis. F1, Factor 1, mild respiratory system symptom; F2, Factor 2, severe system respiratory symptom; F3, Factor 3, susceptibility factor. 
Table 6 MIIC, Cronbach's a coefficient and test-retest reliability of each factor and the whole BARSHSS-CV

\begin{tabular}{lllll}
\hline Factor & Number of Items & MIIC & Cronbach's a & Test-retest reliability \\
\hline Factor 1 & 4 & 0.634 & 0.873 & 0.931 \\
Factor 2 & 9 & 0.656 & 0.945 & 0.944 \\
Factor 3 & 7 & 0.511 & 0.878 & 0.977 \\
BARSHSS-CV & 20 & 0.500 & 0.951 & 0.963 \\
\hline
\end{tabular}

Factor 1, mild respiratory system symptom; Factor 2, severe system respiratory symptom; Factor 3, susceptibility factor. MIIC, mean inter-item correlation coefficients

analysis, Bartlett sphericity test (8705.183, df $=190, P<$ 0.001 ) was significant and the Kaiser-Meyer-Olkin value (0.951) in our study was greater than 0.6 [24]. The above results showed that the scale data were very suitable for factor analysis. The results of exploratory factor analysis indicated 20 items of BARSHSS-CV loaded substantially onto 3 conceptually clear factors. The dimension 3 (medical history) and the dimension 4 (susceptibility factor) in the BARSHSS-CV-II were merged into dimension 3 (susceptibility factor) in the final BARSHSS-CV. The reason for the change of two dimensions may be because the medical history dimension is also essentially the measurement of the susceptibility of the individual's respiratory system. If individuals suffered from related respiratory system diseases in the past, it may indicate that individuals may have some genetic or environmental susceptibility factors, and the probability of recurring respiratory system adverse symptoms may increase correspondingly. Therefore, the research team finally merged the medical history dimension into the susceptibility factor dimension so that the BARSHSS-CV structure becomes more concise, clear and easier to use. In the confirmatory factor analysis, the model goodness of fit is assessed by RMSEA $<0.080$, GFI $>0.900$, IFI $>0.900$, CFI $>0.900$, NFI $>0.900$, TLI $>0.900[14,17,18]$. The results of confirmatory factor analysis in our research met these criteria. The results of confirmatory factor analysis indicate the stability and fit of 3-factor model structure of BARSHSS-CV are both good.

In the internal consistency test of BARSHSS-CV, correlation coefficients between all factors and the whole BARSHSS-CV are from 0.750 to 0.922 , showing that the internal consistency of BARSHSS-CV is good. The values of correlation coefficients between all factors are from 0.416 to 0.699 , showing that the correlation of the factors is a moderate correlation [14]. Thus, the results of BARSHSS-CV show that there is a moderate correlation among different factors. But there are also a certain degree of differences between different factors. Therefore, these factors can measure different aspects of community adult respiratory system health status. Three factors can effectively and comprehensively measure the respiratory system health status of adults in the community.
If items pertaining to the scale can identify the content and topic that we intend to measure, this is referred to as the content validity. The number of expert choices of 3 and 2, which is divided by the total number of experts, represents each item content validity index belonging to the scale. All item content validity indexes make up the average total content validity index [14]. The content validity index of scale was 0.933 . The content validity indexes of all items were from 0.667 to 1.00 . The results indicates that BARSHSS-CV can measure the variables we want to measure; all items can reflect the correct content, and the content validity of BARSHSS-CV is very good.

Mean inter-item correlation (MIIC), Cronbach's alpha and test-retest reliability can be used to evaluate the reliability of scale $[17,25,26]$. When the MIIC of scale is greater than 0.3 , the internal consistency of scale is usually acceptable [26]. The mean inter-item correlation coefficient values of the whole BARSHSS-CV and all factors were greater than 0.5. The usual criterion of a satisfactory internal consistency is a Cronbach's alpha of $\geq 0.7$ [14]. In our research, the Cronbach's alpha value of whole BARSHSS-CV and the Cronbach's alpha values of all factors were greater than 0.8. BARSHSS-CV also reveals a high test-retest reliability over a two week interval, with test-retest reliability coefficients across all dimensions and the whole BARSHSS-CV ranging from 0.931 to 0.977 . Therefore, after the comprehensive analysis, BARSHSS-CV developed in our research has a satisfactory reliability.

\section{Limitations and future direction}

Because of limited study conditions, the scope of sampling needs to be further expanded making BARSHSS-CV more widely verified and applied in more areas of country. BARSHSS-CV can be further improved and revised in the future. A major limitation of this study, and an area for future research should be to investigate the concurrent validity of this new measure with other established questionnaire measures of respiratory health status. Using laboratory examinations and imaging examinations as the measurement golden criterion of the respiratory system health status of adults in the community, it requires a high cost and medical resources. Furthermore, the compliance 
of participants will also significantly decline. Due to the lack of an economical, effective, and appropriate golden criterion for measuring the respiratory system health status of adults in the community, testing the criterion validity of BARSHSS-CV is difficult [17]. In the future study, we will recruit some patients in the respiratory departments of hospitals and compare the BARSHSS-CV score with the results of laboratory examinations and imaging examinations of the patients to further evaluate the sensitivity and specificity of BARSHSS-CV, so that BARSHSS-CV can be more helpful and better for clinical decision. Furthermore, the scale validation in other countries and the cross-cultural scale revision are needed to develop the international application of BARSHSS-CV in the future.

\section{Conclusion}

To sum up, the research has rigorously developed and validated BARSHSS-CV with good internal/re-test reliability and good content/construct validity. BARSHSS-CV is a brief, rapid, effective and economical evaluation tool for extensively assessing the respiratory system health status among community adults in the future. BARSHSS-CV can be used to assess the respiratory system health status of adults in the community, help medical staff in health care institutions conduct targeted interventions, as well as provide health guidance for community adults relating to the health care of the respiratory system and help community adults establish a healthy lifestyle.

\section{Additional files}

\section{Additional file 1: The item pool. The initial pool of 40 items.} (DOCX $14 \mathrm{~kb}$ )

Additional file 2: BARSHSS-CV-I. The content of the brief adult respiratory system health status scale-community version-I(BARSHSS-CV-I). (DOCX $16 \mathrm{~kb}$ )

\section{Abbreviations \\ BARSHSS-CV: Brief adult respiratory system health status scale-community version; CFA: Confirmatory factor analysis; CFI: Comparative fit index; CVl: Content validity index; df: Degrees of freedom; EFA: Exploratory factor analysis; GFI: Goodness of fit index; IFI: Incremental fit index; KMO: Kaiser- Meyer-Olkin; MIIC: Mean inter-item correlation coefficients; NFI: Normed fit index; PCA: Principal component analysis; RMSEA: Root-mean-square error of approximation; TLI: Tueker-Lewis index; 2 /df: Chi square value/degrees of freedom; $\times 2$ : Chi square value}

\section{Acknowledgements}

Authors would like to thank Rong Xiao Ph.D., Linhong Yuan Ph.D., Cui Zhou Ph.D., School of Public Health of Capital Medical University, for their help in this study.

\section{Funding}

This study was supported by a grant from Hebei Province Federation of Social Science Circles (No. 201501808), a grant from Health and Family Planning Commission of Hebei (No. 20150072) and a grant from Health and Family Planning Commission of Hebei (No. 20180707). The funders had no role in the design of the study and collection, analysis, or the interpretation of data and writing of the manuscript.

\section{Availability of data and materials}

The data that support this analysis may be available on reasonable request from the corresponding author. They are not publicly available as they contain information that could compromise research participant privacy and consent.

\section{Authors' contributions}

Conceived and designed the study (HZD, YJZ, LWT); Collected data and analyzed data (YHC, QCZ, BX, YW, YHZ, ZGC, JG); Wrote the manuscript (HZD, YJZ, LWT). All authors read and approved the final manuscript.

\section{Ethics approval and consent to participate}

The Hebei province federation of social science circles approved this study (Permit Number: 201501808). This research was conducted according to the standards of the Declaration of Helsinki. In order to save participants' time and improve the response rate of participants, the verbal consent was obtained from participants. Obtaining only verbal consent was approved by the ethics committee. The research team explained the purpose of this study to the adults in the communities. After the permission of adults in the communities, on the spot, the researchers guided the community adults how to complete the questionnaires.

\section{Consent for publication}

Not Applicable.

\section{Competing interests}

The authors declare that they have no competing interests.

\section{Publisher's Note}

Springer Nature remains neutral with regard to jurisdictional claims in published maps and institutional affiliations.

\section{Author details}

${ }^{1}$ Affiliated Hospital of Hebei University, No.212 Yuhua East Road, Baoding 071000, China. ${ }^{2}$ The NO.5 Hospital of Baoding, No.340 Ruixiang Street, Baoding 071000, China. ${ }^{3}$ College of Nursing, Hebei University, No.342 Yuhua East Road, Baoding 071000, China. ${ }^{4}$ School of Public Health, Capital Medical University, No.10 Xitoutiao, Youanmenwai, Beijing 100069, China.

Received: 16 April 2018 Accepted: 29 August 2018

Published online: 03 September 2018

\section{References}

1. Sierra-Vargas MP, Teran LM. Air pollution: impact and prevention. Respirology. 2012;17(7):1031-8.

2. Chen Z, Wang JN, Ma GX, Zhang YS. China tackles the health effects of air pollution. Lancet. 2013;382(9909):1959-60.

3. Ge J, Xu Y. Internal medicine. 8th ed. Beijing: People's Medical Publishing House; 2013.

4. Croft JB, Wheaton AG, Liu Y, Xu F, Lu H, Matthews KA, Cunningham TJ, Wang Y, Holt JB. Urban-Rural County and state differences in chronic obstructive pulmonary disease - United States, 2015. MMWR Morb Mortal Wkly Rep. 2018;67(7):205-11.

5. Farah C, Hosgood HD 3rd, Hock JM. Spatial prevalence and associations among respiratory diseases in Maine. Spatial and spatio-temporal epidemiology. 2014;11:11-22

6. To T, Stanojevic S, Moores G, Gershon AS, Bateman ED, Cruz AA, Boulet LP. Global asthma prevalence in adults: findings from the cross-sectional world health survey, BMC Public Health. 2012:12:204

7. Ferrante G, Baldissera S, Campostrini S. Epidemiology of chronic respiratory diseases and associated factors in the adult Italian population. Eur J Pub Health. 2017;27(6):1110-6.

8. Migliaretti G, Dalmasso P, Gregori D. Air pollution effects on the respiratory health of the resident adult population in Turin, Italy. Int J Environ Health Res. 2007;17(5):369-79

9. Zhou M, He G, Liu Y, Yin P, Li Y, Kan H, Fan M, Xue A, Fan M. The associations between ambient air pollution and adult respiratory mortality in 32 major Chinese cities, 2006-2010. Environ Res. 2015;137:278-86.

10. Wu MY, Wu TI, Tseng YH, Shen WC, Chang YS, Huang CC, Lin PJ. The feasibility of venovenous extracorporeal life support to treat acute respiratory failure in adult cancer patients. Medicine. 2015;94(21):e893. 
11. Jonsdottir H. Nursing care in the chronic phase of COPD: a call for innovative disciplinary research. J Clin Nurs. 2008;17(7B):272-90.

12. Sun Z, Xu Y. Medical statistics. 4th ed. Beijing: People's Medical Publishing House; 2014.

13. Billings-Gagliardi S, Mazor KM. Development and validation of the stroke action test. Stroke. 2005;36(5):1035-9.

14. Zhao Q, Yang L, Zuo Q, Zhu X, Zhang X, Wu Y, Yang L, Gao W, Li M. Instrument development and validation of the stroke pre-hospital delay behavior intention scale in a Chinese urban population. Health Qual Life Outcomes. 2014;12:170.

15. Gao J, Woodward A, Vardoulakis S, Kovats S, Wilkinson P, Li L, Xu L, Li J, Yang J, Li J, et al. Haze, public health and mitigation measures in China: a review of the current evidence for further policy response. Sci Total Environ. 2017;578:148-57

16. Xu Y. Social survey design and data analysis - from topic to publication. Chongqing: Chongqing University Press; 2011.

17. Zhang Q, Huang F, Liu Z, Zhang N, Mahapatra T, Tang W, Lei Y, Dai Y, Tang $\mathrm{S}$, Zhang J. Cross-cultural validation of the high blood pressure health literacy scale in a Chinese community. PLoS One. 2016;11(4):e0152182.

18. Sun T, Zhao XW, Yang LB, Fan LH. The impact of psychological capital on job embeddedness and job performance among nurses: a structural equation approach. J Adv Nurs. 2012:68(1):69-79.

19. Janiszewski D, O'Brian CA, Lipman RD. Patient experience in a coordinated care model featuring diabetes self-management education integrated into the patient-centered medical home. The Diabetes educator. 2015;41(4):46671.

20. Blondon KS. Patient attitudes about financial incentives for diabetes selfmanagement: a survey. World J Diabetes. 2015;6(5):752-8.

21. Li P, Gong Y, Zeng G, Ruan L, Li G. A new mode of community continuing care service for COPD patients in China: participation of respiratory nurse specialists. Int J Clin Exp Med. 2015;8(9):15878-88.

22. Hedley AJ, McGhee SM, Barron B, Chau P, Chau J, Thach TQ, Wong TW, Loh C, Wong CM. Air pollution: costs and paths to a solution in Hong Kong-understanding the connections among visibility, air pollution, and health costs in pursuit of accountability, environmental justice, and health protection. Journal of toxicology and environmental health Part A. 2008; 71(9-10):544-54.

23. Ekback M, Benzein E, Lindberg M, Arestedt K. The Swedish version of the multidimensional scale of perceived social support (MSPSS)--a psychometric evaluation study in women with hirsutism and nursing students. Health Qual Life Outcomes. 2013;11:168.

24. Mills RJ, Young CA, Pallant JF, Tennant A. Development of a patient reported outcome scale for fatigue in multiple sclerosis: the neurological fatigue index (NFI-MS). Health Qual Life Outcomes. 2010;8:22.

25. Reissmann DR, Benecke AW, Aarabi G, Sierwald I. Development and validation of the German version of the orofacial esthetic scale. Clin Oral Investig. 2015;19(6):1443-50.

26. Komagamine $Y$, Kanazawa M, Kaiba Y, Sato Y, Minakuchi S. Reliability and validity of a questionnaire for self-assessment of complete dentures. BMC oral health. 2014;14:45

Ready to submit your research? Choose BMC and benefit from:

- fast, convenient online submission

- thorough peer review by experienced researchers in your field

- rapid publication on acceptance

- support for research data, including large and complex data types

- gold Open Access which fosters wider collaboration and increased citations

- maximum visibility for your research: over $100 \mathrm{M}$ website views per year

At BMC, research is always in progress.

Learn more biomedcentral.com/submissions 